Sharif University of Technology
Scientia Iranica
SCIENTIA
IRAN I CA
Transactions A: Civil Engineering
www.scientiairanica.com

\title{
Reliability of Tehran transportation network during earthquakes
}

\author{
K. Shabani ${ }^{a}$ and H. Nassiri $i^{b, *}$ \\ a. Department of Civil and Engineering, Portland State University, P.O. Box 751, Portland, Oregon, USA. \\ b. Department of Civil Engineering, Sharif University of Technology, P.O. Box 11155-4313, Tehran, Iran. \\ Received 14 May 2014; received in revised form 4 July 2015; accepted 5 January 2016
}

\section{KEYWORDS \\ Earthquake; \\ Reliability; \\ Connectivity; \\ Simulation; \\ Transportation \\ network.}

\begin{abstract}
Tehran is the capital of Iran and is one of the largest cities in the world. With its history of earthquakes, high population density, and a population of over 8.5 million, it must be prepared to cope with disaster. This article introduces a new method for estimating the reliability of a roadway network that considers the physical characteristics of the road and link capacity degradation. The proposed method was applied to a real road network and the connectivity reliability of the city was calculated. The proposed technique for computing connectivity reliability is sensitive to the characteristics of the road and adjacent buildings. The results indicate that northern Tehran, with a low population density and newer buildings and highway network, shows higher reliability for origin and destination trips than other regions. This region has a higher probability of connectedness to other regions after a disaster. The weakest area of the network lies in the southern and central regions with older buildings and no highway network. These regions show low connectivity reliability and high population density. These results provide useful insights into the vulnerability of the Tehran network in response to a major earthquake.
\end{abstract}

(C) 2016 Sharif University of Technology. All rights reserved.

\section{Introduction}

The seismic records for the Iran's capital city of Tehran show that the probability of occurrence of a strong earthquake is very high. Tehran is located on three major seismic faults (Mosha, Ray, and North) and history shows that a major earthquake occurs in Tehran approximately every 150 years. The last major earthquake occurred in 1830 , which means that the city is overdue [1].

During the 20th century, transportation programs focused on the development of basic infrastructure for the transportation network. In the present century,

*. Corresponding author. Tel.: +98 21 66164201; Fax: +982166014828

E-mail addresses: kaveh@pdx.edu (K. Shabani);

nassiri@sharif.edu (H. Nassiri) the focus has shifted to management and operation of these networks. Regular traffic flow in a transportation network is subject to interruptions and failures having different lag times caused by factors such as accidents and natural disasters. The lag time between interruptions may vary from hours for an accident to years for an earthquake [1]. After a major disaster, finding a reliable path for rescue and evacuation vehicles to each emergency site is vital to reduce indirect loss and manage the disaster.

The present study measured the reliability and predicted post-disaster performance of Tehran's transportation network using a new method based on network simulation. The method calculates the reliability of O-D pairs assuming a hypothetical earthquake in Tehran. This method features: (a) an evaluation of existing connectivity reliability for the real transportation network; (b) a new simulation method for 
estimating connectivity reliability; and (c) the expected post-disaster performance of Tehran's transportation network.

\section{Literature review}

Research on transportation network reliability focuses on connectivity, travel time, and capacity. Connectivity reliability is the probability of connections between network nodes remaining open. This probability seeks for possible routes between an origin and a destination (O-D pair). It is assumed that if one route exists between an O-D pair, then the network is functional. For this type of reliability measure, capacity constraints on links are not considered [2]. This method is not suitable for day-to-day studies and is usually reserved for disaster mitigation. Nicholson and Du [3] introduced a theoretical framework for transportation system reliability and estimated the connectivity reliability of a degradable transportation network in which connectivity reliability was defined as the probability of all O-D pairs remaining connected in different road closure scenarios.

Travel time reliability is the probability of travel between an O-D pair at a predefined level of service (travel time). This measure is suitable for day-to-day traffic conditions and has been defined as the difference between expected travel time (scheduled or average travel time) and actual travel time [4]. Bell and Iida [5] introduced travel time reliability for O-D pairs using a pre-defined time interval and acceptable level of service. They later proposed a method based on sensitivity analysis to estimate variation in travel time in response to fluctuations in daily traffic demand [6].

Asakura [7] estimated travel time reliability by considering reduced capacity caused by failure of roads. He considered travel time reliability to be a function of the ratio of reduced conditions to normal conditions when evaluating the performance of a transportation network. This type of reliability is used to define a suitable Level Of Service (LOS) that is compatible with known link failures.

Capacity reliability is the probability of the capacity of a network to successfully pass a predefined level of O-D pair demands at an acceptable level of service [8]. This measure is suitable for evaluation of LOS conditions for system managers. The concept of network capacity reliability was first proposed by Chen et al. [9], who defined it as a uniform multiplier of all O$\mathrm{D}$ demands that generates an equilibrium link flow that satisfies link capacity. The introduction of link capacity ensures a satisfactory level of service on all links in the network (e.g., non-congested condition). In their study, O-D demand multipliers were allowed to differ in response to O-D movements that represented traffic demand regulation parameters. They defined capacity reliability for a specific traffic regulation strategy as the probability of the regulation strategy generating the allowed traffic volume in the network being greater than that for the specified criteria using random link capacity.

Chen et al. [10] also proposed a capacity reliability index that used connectivity reliability as a special case and travel time reliability as a side result. They extended their initial analysis of capacity reliability to provide a comprehensive methodology that combined reliability, uncertainty, network equilibrium models, sensitivity analysis, and Monte Carlo simulation to assess the performance of a degradable network. They provided numerical results applying their method to a simple network. Chen et al. [11] further studied the effects of route choice models on estimation of capacity reliability. They found that travelers having different behaviors preferred specific links in response to their risk preferences.

Sumalee and Watling [4] considered driver behavior when developing a framework and algorithm to estimate bounds for the probability of path travel time exceeding a specific threshold in response to dependent multi-mode link failures. They tested their method on a small network by assuming that only drivers on the directly affected links were adaptable (partial equilibrium). They stated that causal factors could cause dependent link failure and not all drivers would be aware of degraded links and conditions. They demonstrated that it is possible to formulate a causerelated version of the travel time reliability problem by relaxing the usual assumptions of independent link failure and fully adaptive driver response.

Few studies have addressed the connectivity reliability of a transportation network under disaster conditions using real data. Nojima and Chang [12] studied the transportation network after the Northridge earthquake. They applied length of highways, accessibility, and retrieval of traffic volume to evaluate the performance of a network after the earthquake. They compared the performances of the transportation networks after Loma Prieta (1987), Northridge (1994), and Kobe (1995) earthquakes and the economic impact of the Northridge earthquake.

Kawakami [13] used Monte Carlo simulation to account for seismicity, ground conditions, and the strength of the structures in the system to produce failure patterns in a transportation network. He developed a detailed method using flow analysis and accounted for the effects of decreased capacity of the road after an earthquake when examining functional damage and the role of each road of the highway system in the performance of the network. Jiang et al. [14] established a connectivity reliability evaluation model for road sections, roads, and road networks. Their research provides a theoretical basis for planning and 
construction of road networks and disaster prevention in high-intensity earthquake zones.

Khademi et al. [15] proposed post-disaster vulnerability analysis for an emergency transportation network. The traffic zone susceptible to disruption by an earthquake was identified using a post-recovery response and recovery approach. Liu et al. [16] constructed a transportation system network connectivity analysis model combined with graph theory and network analysis theories and methods. The Warshall algorithm was used for fuzzy mathematical manipulation and a reachability matrix was developed to decide on the connectivity of the transportation system network. Li et al. [17] established a transportation network reconstruction model based on connectivity reliability for the post-disaster emergency phase.

Mohaymany et al. [18] used a time-space accessibility measure based on expected performance of a network after an earthquake. The upper and lower bounds method was used to estimate the accessibility reliability to identify critical infrastructures in a road network. Yang et al. [19] combined travel time and capacity reliability in a small network and presented a comprehensive index for evaluation of transportation network performance. They used a 2D graphical method to study the two reliability measures for different traffic demand and serviceability situations. Gertsbakh and Shpungin [20] proposed an improvement to network reliability by reinforcement of important links subject to failure. The reinforcement was subject to budgetary constraints. In the proposed optimization, a combinatorial Monte-Carlo algorithm was used to estimate network space-time reliability and its gradient vector. Emam et al. [21] introduced a new method for calculating travel time reliability in a highway network. They examined probability distribution functions and concluded that a lognormal distribution provided the best distribution.

Gunnec and Salman [22] calculated the connectivity reliability of a small highway network in Istanbul using a Monte Carlo simulation. They computed the connectivity reliability for independent and dependent link failures. Their results show that the reliability and performance of a network in both cases can be estimated with high accuracy in a moderate CPU time. Sumalee and Kurauchi [2] used Monte Carlo simulation to evaluate network reliability based on capacity reliability. They concluded that the flexibility of the Monte Carlo simulation comes with the trade-off of a potentially high computational burden. Sumalee and Watling [23] proposed an algorithm to approximate the network reliability, which minimized the use of simulation. Their algorithm classified the network conditions as reliable, unreliable, and undetermined. They also proposed a cause-based failure framework to represent the probability of dependent link degra- dation. They tested the proposed algorithm with a medium-size test network to illustrate the performance of the algorithm.

A new algorithm is proposed that is written in MATLAB and used to estimate the connectivity reliability of Tehran transportation network. The present study introduces a new perspective for network performance after a natural disaster by implementing the proposed algorithm on a real network. The major distinction of this study from those reviewed in the literature is consideration of the effects of structure failure (bridges and buildings) and their characteristics (height, width, type of structure) on adjacent links after an earthquake. These characteristics have been recorded in a comprehensive governmental report and the results have been used to compute the probability of building failure by assuming that building failure is the major factor causing damage to an adjacent link. An algorithm using these characteristics was developed and is described to estimate connectivity reliability.

\section{Problem definition and methodology}

The present study introduces a new algorithm in which buildings adjacent to a roadway affect the functional performance of the road to estimate connectivity reliability of a real roadway network. This section describes the network and the data used. It also discusses the assumptions and procedure used to evaluate the Tehran transportation network.

\subsection{Data and network}

The transportation network consisted of nearly 400 nodes and 1500 links covering all freeways, highways, major and minor arterials, collectors, and local access roads in the Tehran roadway network (Figure 1). Figure 2 shows the municipality districts used for assignment. Table 1 lists the O-D demand data. In this table, information on speed and capacity of each link [24] and its functional classification, width, and length [25] is provided. Figure 1 shows that the central

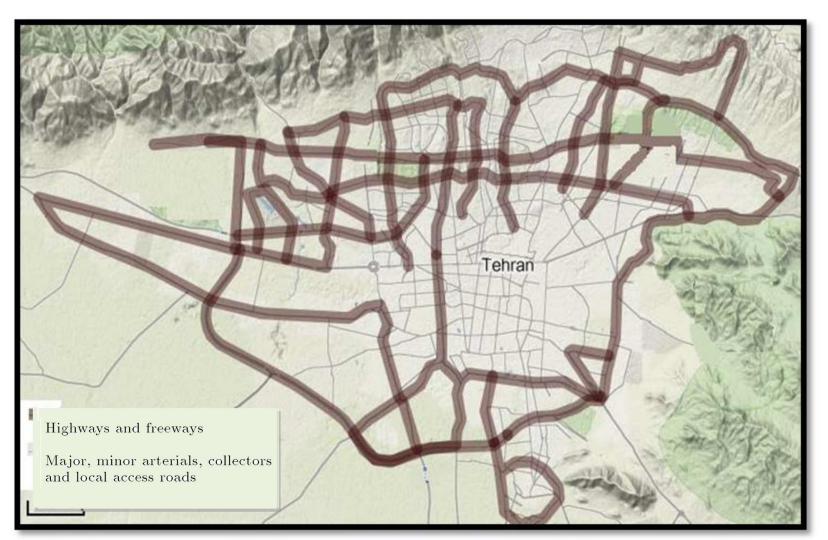

Figure 1. Tehran transportation network. 
Table 1. Sample network data.

\begin{tabular}{|c|c|c|c|c|c|c|c|}
\hline $\begin{array}{l}\text { Starting } \\
\text { node }\end{array}$ & $\begin{array}{c}\text { Ending } \\
\text { node }\end{array}$ & Type & $\begin{array}{c}\text { Width } \\
(\mathrm{m})\end{array}$ & $\begin{array}{c}\text { Free-flow speed } \\
(\mathrm{km} / \mathrm{h})\end{array}$ & $\begin{array}{l}\text { Length } \\
(\mathrm{m})\end{array}$ & $\begin{array}{c}\text { Free-flow travel } \\
\text { time }\end{array}$ & $\begin{array}{l}\text { Capacity } \\
(\mathrm{pc} / \mathrm{h} / \mathrm{l})\end{array}$ \\
\hline 1 & 2 & Minor arterial & 10 & 50 & 5812.5 & 418.5 & 2000 \\
\hline 1 & 37 & Major arterial & 12 & 60 & 4312.5 & 258.7 & 3000 \\
\hline 2 & 3 & Major arterial & 12 & 60 & 2212.5 & 132.7 & 3000 \\
\hline 9 & 10 & Local access & 3 & 30 & 1125 & 135 & 300 \\
\hline 9 & 28 & Local access & 3 & 30 & 375 & 45 & 300 \\
\hline 4 & 5 & Major arterial & 12 & 60 & 450 & 27 & 3000 \\
\hline 4 & 42 & Highway & 15 & 90 & 1575 & 63 & 4500 \\
\hline 5 & 35 & Major arterial & 12 & 60 & 1312.5 & 78.7 & 3000 \\
\hline 5 & 44 & Collector & 5 & 40 & 1687.5 & 151.8 & 825 \\
\hline
\end{tabular}

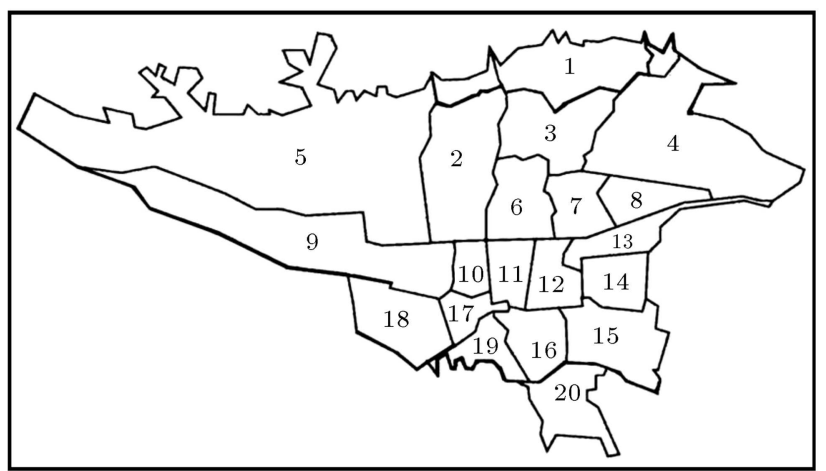

Figure 2. Tehran municipality districts in 2002.

part of the network is free of highways and freeways, which is a major weakness in this region.

Data about the network was collected to compute the reliability for all O-D pairs (20 districts) in the Tehran transportation network, where the links were subject to failure after a natural disaster. The data includes network configuration, practical capacity of the link, volume-delay function of the link, and O-D demand matrix. The travel time/capacity functions were next assigned and the O-D demand matrix for Tehran was estimated based on the data. Table 2 provides travel time/capacity functions for the road types used for traffic assignment. Figure 3 shows the volume on travel links in the network as estimated

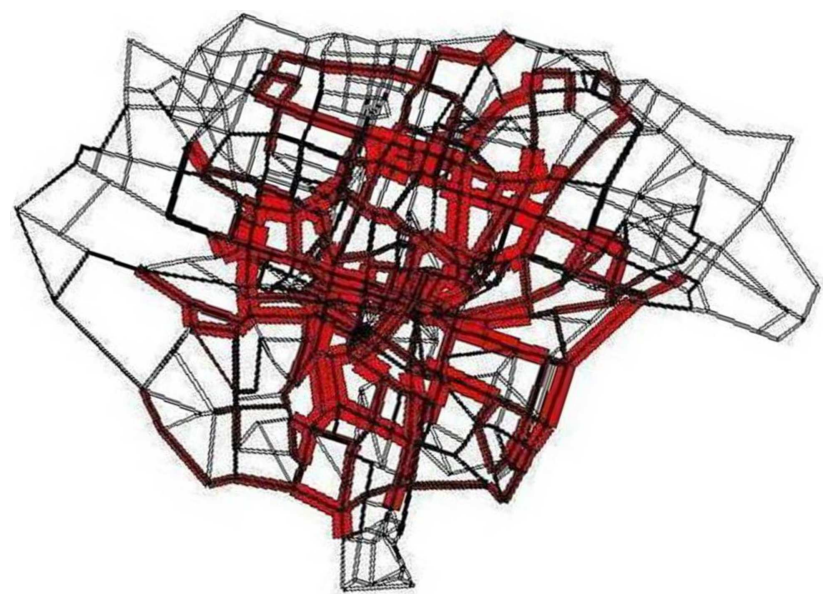

Figure 3. Traffic assignments showing auto volume on links.

using EMME/2 for traffic assignment. EMME/2 is an interactive-graphic multimodal urban transportation planning system for static assignment using numerical optimization.

\subsection{Methodology}

It is assumed that in an emergency condition, such as an earthquake, network links fail dependently. When the disaster involves a large area and alternative routes are not considered, it is reasonable to consider dependent failure of the links. Dependent failure

Table 2. Travel time/capacity functions [24].

\begin{tabular}{cl}
\hline Type & Travel time/capacity functions \\
\hline Local access & $\mathrm{fd} 1=$ length $\times 1.5 \times\left(1+0.15 \times(\text { volau } / 300)^{4}\right)$ \\
Collector & $\mathrm{fd} 2=$ length $\times 1.5 \times\left(1+0.15 \times(\text { volau } / 825)^{4}\right)$ \\
Minor arterial & $\mathrm{fd} 3=$ length $\times 1.2 \times\left(1+0.15 \times(\text { volau } / 2000)^{4}\right)$ \\
Major arterial & $\mathrm{fd} 4=$ length $\times 1 \times\left(1+0.15 \times(\text { volau } / 3000)^{4}\right)$ \\
Freeways and highways & $\mathrm{fd} 5=$ length $\times 0.75 \times\left(1+0.15 \times(\text { volau } / 4500)^{4}\right)$ \\
Dummy link & $\mathrm{fd} 6=$ length $\times 1.5$ \\
Volau: link volume in auto scale &
\end{tabular}

Volau: link volume in auto scale 
occurs when one link of a series of connected links fails and causes the whole series to be considered as failed because there is only one path considered to be the shortest path. Some links may act as a group and fail simultaneously [25]. Link failure can be related to either inside factors (failure of a bridge) or outside factors (earthquake force). Inside factors are considered in this study to be the cause of link failure and are considered to be dependent. If one link in a route between an O-D pair fails, the other links cannot be used and the route becomes non-functional. Link failure is calculated using the following major assumptions:

- Only the failure of bridges and buildings adjacent to the link affect link malfunction. Fallen trees, electric/utility cables, broken water pipes, large cracks in the roadways, and other potential problems could also cause road failure, but the data available for Tehran considered only bridge and building failure;

- If the probability of survival of a link (assumed to be random) is equal to or greater than the probability of failure, then the link is assumed to be operational; otherwise, the link is assumed to have failed;

- Only one random number will be generated for each path for probability of survival. This is assumed to represent the probability of survival of all links on that path after the earthquake. The failure probability of all links on that path is compared to the survival probability;

- The reliability of the path between each O-D pair is calculated as the number of situations that the result in comparison of all links in the path that equals 1 (i.e. survival probability $\geq$ failure probability), divided by the total number of situations in which random numbers are generated. The percentage of cases (total occurring in hypothetical earthquake) in which all links in the path survive is assumed to be the connectivity reliability. In this study, the reliabilities converged when the random numbers were generated 100000 times and the final reliability was calculated. This means that for every 100000 generations of earthquake occurrence, the difference between the reliabilities calculated in the two phases is negligible. The reliability of all O-D pairs in the network is calculated as described.

\subsubsection{Steps of algorithm}

1. Input the link data and failure probability of links and execute traffic assignment. Traffic is assigned to the network links using EMME/2. The input data includes node information, link information, O-D demand matrix, and travel time/capacity function. The latest available data [24] is used at real network size. The input files for EMME/2 are prepared, traffic assignment executed, and the volumes on travel links of the network estimated (Figure 3 ). The probability of failure of buildings in each region for all links (percentage of buildings that have failed in that region after an earthquake [26]) and the network data are inputted into MATLAB for simulation;

2. Generate random numbers for the probability of link survival. Random numbers are generated as the probability of a link functioning after the hypothetical earthquake. Uniform distribution is assumed for generation of random numbers. Only one random number is generated for each path and it is assumed to represent the probability of survival of all links on that path after the earthquake. This random number is generated in multiples of ten for each path. The reliabilities converge when the random numbers are generated 100000 times and the final reliability is calculated. This means that for every 100000 times that an earthquake occurs, the proportion of times in which the shortest path between each O-D pair survives remains unchanged; this is the final reliability of that O-D pair;

3. Compare the probability of link failure and link survival for each link for the shortest path obtained by traffic assignment. Only one path (the shortest path extracted from the outcomes of EMME2) is used for each O-D pair for comparison of the probability of link failure and link survival. The probability of link failure for all links in that path is compared with probability of survival. If the survival probability (a random number) is equal to or higher than the failure probability, then that link is assumed to be operational (equal to 1). Otherwise, the link is assumed to have failed and the result equals zero;

4. Calculate the reliability by obtaining the ratio of active routes for all routes between $\mathrm{O}-\mathrm{D}$ pairs. The reliability of the path between each O-D pair is first calculated. This is obtained by dividing the number of times that the result of comparison for all links in the path equals 1 by the total number of times that the random numbers are generated. In other words, the number of times in which all links in the path survive after the hypothetical earthquake to the total number of times that the earthquake occurs represents the connectivity reliability.

\subsubsection{Variables of algorithm}

Figure 4 shows the pseudo-code of the algorithm written in MATLAB. The variables applied in the algorithm are:

- Matrix A: Input data for link characteristics and failure probability;

- Matrix B: Shortest path between O-D pairs derived from traffic assignment using EMME/2; 


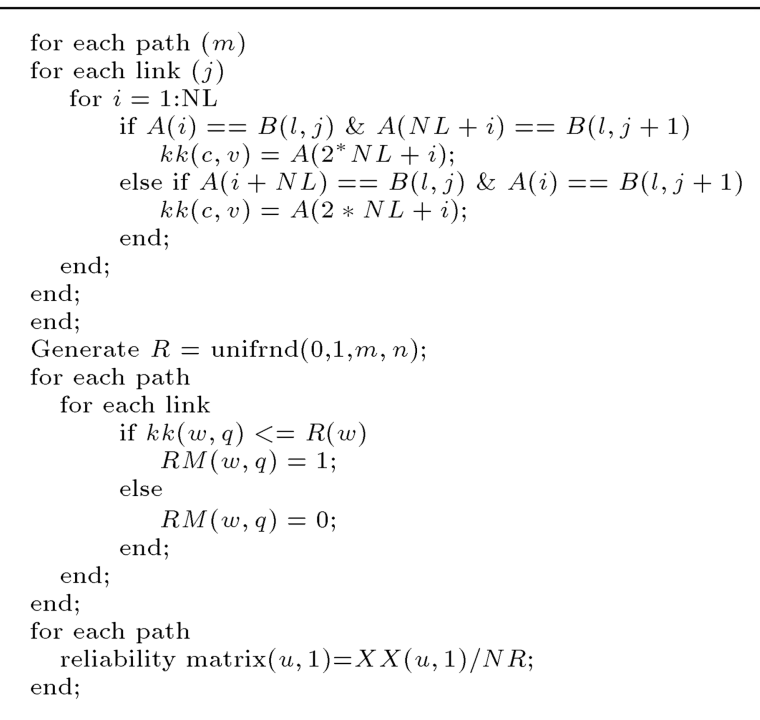

Figure 4. Pseudo-code of algorithm written in MATLAB.

- M: Number of the shortest paths between O-D pairs;

- NL: Number of links in matrix A;

- KK: Link failure probability matrix;

- R: Random numbers generated as survival probabilities;

- RM: 0/1 matrix for comparison of survival and failure probabilities of links;

- NR: Number of randomly generated probabilities.

\subsubsection{Assumptions of algorithm}

The data available from a governmental report for seismic micro-zoning in Tehran [26] was used to calculate the probability of failure of buildings during calculation of the probability of link failure (Tables 3 and 4). The following assumptions were made:
- Only the failure of bridges and buildings adjacent to the link affects link failure;

- The probability of failure of buildings in each district for all links equals the type of structure plus the percentage of buildings that have failed in that district as a result of the hypothetical earthquake;

- A hypothetical earthquake along the Ray fault in southern Tehran affected the network. This fault has caused the most damage in previous earthquakes [26];

- All buildings in each district have the same probability of failure;

- For links on the border between two districts, the average probability of failure of buildings in both districts is used as the failure probability for the buildings adjacent to that link. In other words, links on the border of two districts are considered to belong to both districts;

- The height of each building is assumed to be 3.5 times the number of stories; this is typical of buildings in Iran;

- The height of a failed building is equal to onethird of the height of that building, signifying that one-third of the height will cover the road after an earthquake;

- The percentage of link damage caused by failure of adjacent buildings is calculated as the height of the damaged building that has collapsed divided by the width of the link;

- The probability of building failure of damaged buildings in each district is calculated by assuming an earthquake of magnitude 7.0 on the Richter scale using the results of the comprehensive governmental report [26];

Table 3. Sample failure probabilities of links.

\begin{tabular}{|c|c|c|c|c|c|c|c|c|c|}
\hline $\begin{array}{l}\text { Origin } \\
\text { node }\end{array}$ & $\begin{array}{l}\text { End } \\
\text { node }\end{array}$ & $\begin{array}{l}\text { Type of } \\
\text { link }\end{array}$ & $\begin{array}{l}\text { Width of } \\
\text { link } \\
(\mathrm{m})\end{array}$ & $\begin{array}{c}\text { Average } \\
\text { number of } \\
\text { stories }\end{array}$ & $\begin{array}{l}\text { Average } \\
\text { height of } \\
\text { buildings } \\
\text { (m) }\end{array}$ & $\begin{array}{l}\text { Failure } \\
\text { length } \\
(\mathrm{m})\end{array}$ & $\begin{array}{c}\text { Link } \\
\text { damage } \\
\text { caused by } \\
\text { building } \\
\text { failure } \\
(\%)\end{array}$ & $\begin{array}{c}\text { Building } \\
\text { failure } \\
\text { probability } \\
\text { (\%) }\end{array}$ & $\begin{array}{c}\text { Link } \\
\text { failure } \\
\text { probability } \\
(\%)\end{array}$ \\
\hline 1 & 2 & Minor arterial & 10 & 3.45 & 12.08 & 4.03 & 40.25 & 31.00 & 12.48 \\
\hline 274 & 275 & Major arterial & 12 & 4.04 & 14.14 & 4.71 & 39.00 & 61.00 & 24.00 \\
\hline 4 & 5 & Major arterial & 12 & 3.45 & 12.08 & 4.03 & 33.54 & 31.00 & $100.00^{*}$ \\
\hline 4 & 42 & Highway & 15 & 3.45 & 12.08 & 4.03 & 26.83 & 31.00 & 8.32 \\
\hline 5 & 35 & Major arterial & 12 & 3.45 & 12.08 & 4.03 & 33.54 & 31.00 & 10.40 \\
\hline 5 & 44 & Collector & 5 & 3.45 & 12.08 & 4.03 & 80.50 & 31.00 & 24.96 \\
\hline 6 & 7 & Minor arterial & 10 & 3.45 & 12.08 & 4.03 & 40.25 & 31.00 & 12.48 \\
\hline
\end{tabular}

* Link containing collapsed bridge after hypothetical earthquake. 
Table 4. Reliability matrix (\%) for O-D pairs.

\begin{tabular}{ccccccccccccccccccccc}
\hline & $\mathbf{1}$ & $\mathbf{2}$ & $\mathbf{3}$ & $\mathbf{4}$ & $\mathbf{5}$ & $\mathbf{6}$ & $\mathbf{7}$ & $\mathbf{8}$ & $\mathbf{9}$ & $\mathbf{1 0}$ & $\mathbf{1 1}$ & $\mathbf{1 2}$ & $\mathbf{1 3}$ & $\mathbf{1 4}$ & $\mathbf{1 5}$ & $\mathbf{1 6}$ & $\mathbf{1 7}$ & $\mathbf{1 8}$ & $\mathbf{1 9}$ & $\mathbf{2 0}$ \\
\hline 1 & - & 82 & 78 & 92 & 84 & 80 & 85 & 84 & 81 & 85 & 65 & 75 & 81 & 67 & 75 & 71 & 82 & 80 & $\mathbf{0}$ & 76 \\
2 & 82 & - & 82 & 84 & 84 & 82 & 82 & 82 & 81 & 78 & 76 & $\mathbf{0}$ & 78 & $\mathbf{0}$ & 76 & 76 & 84 & 80 & $\mathbf{0}$ & $\mathbf{0}$ \\
3 & 78 & 82 & - & 82 & 82 & 82 & 85 & 82 & 81 & 82 & 77 & 75 & 78 & 77 & 78 & 71 & 82 & 80 & $\mathbf{0}$ & $\mathbf{0}$ \\
4 & 93 & 84 & 82 & - & 84 & 82 & 85 & 81 & 81 & 84 & 65 & 75 & 84 & 84 & 84 & 75 & 82 & $\mathbf{0}$ & $\mathbf{0}$ & 76 \\
5 & 84 & 84 & 82 & 84 & - & 73 & 84 & 84 & 81 & 81 & 76 & 71 & 78 & $\mathbf{0}$ & 77 & 77 & 84 & 80 & 83 & $\mathbf{0}$ \\
6 & 82 & 82 & 82 & 82 & 73 & - & 75 & 78 & 71 & 71 & 65 & $\mathbf{0}$ & $\mathbf{0}$ & $\mathbf{0}$ & $\mathbf{0}$ & $\mathbf{0}$ & $\mathbf{0}$ & 71 & $\mathbf{0}$ & $\mathbf{0}$ \\
7 & 85 & 82 & 85 & 85 & 84 & 75 & - & 79 & 73 & 71 & 65 & 76 & 83 & 83 & 81 & 80 & 71 & 71 & $\mathbf{0}$ & 76 \\
8 & 85 & 82 & 82 & 81 & 84 & 78 & 79 & - & 73 & 71 & 65 & 75 & 81 & 81 & 81 & 75 & 71 & $\mathbf{0}$ & $\mathbf{0}$ & 76 \\
9 & 81 & 81 & 81 & 81 & 81 & 76 & 73 & 73 & - & 62 & 65 & 65 & 62 & 71 & 81 & 80 & 84 & 80 & 83 & $\mathbf{0}$ \\
10 & 80 & 78 & 80 & 80 & 81 & 76 & 73 & 73 & 62 & - & 76 & 71 & 71 & 71 & 81 & 81 & 81 & 80 & $\mathbf{0}$ & $\mathbf{0}$ \\
11 & 78 & 73 & 78 & 71 & 76 & $\mathbf{0}$ & $\mathbf{0}$ & 71 & 65 & 71 & - & 71 & $\mathbf{0}$ & 76 & 71 & 76 & 65 & 65 & $\mathbf{0}$ & 71 \\
12 & 76 & $\mathbf{0}$ & 76 & 78 & 71 & $\mathbf{0}$ & 76 & 75 & 65 & 71 & 71 & - & 76 & 79 & 79 & 75 & 71 & 71 & $\mathbf{0}$ & 79 \\
13 & 81 & 78 & 78 & 85 & 78 & $\mathbf{0}$ & 83 & 81 & 62 & 71 & $\mathbf{0}$ & 76 & - & 85 & 81 & 62 & 71 & $\mathbf{0}$ & $\mathbf{0}$ & 76 \\
14 & 67 & $\mathbf{0}$ & 78 & 85 & 0 & $\mathbf{0}$ & 82 & 81 & 71 & 71 & 76 & 79 & 85 & - & 81 & 80 & 61 & $\mathbf{0}$ & $\mathbf{0}$ & 76 \\
15 & 75 & 76 & 76 & 84 & 77 & $\mathbf{0}$ & 81 & 81 & 81 & 81 & 71 & 79 & 81 & 81 & - & 80 & 79 & $\mathbf{0}$ & $\mathbf{0}$ & 76 \\
16 & 75 & 71 & 71 & 75 & 71 & $\mathbf{0}$ & 80 & 75 & 71 & 71 & 76 & 75 & 62 & 80 & 81 & - & 79 & $\mathbf{6 1}$ & $\mathbf{0}$ & 77 \\
17 & 84 & 84 & 82 & 84 & 84 & 71 & 71 & 71 & 84 & 79 & 65 & 71 & 71 & 61 & 79 & 79 & - & 80 & 79 & $\mathbf{0}$ \\
18 & 80 & 80 & 80 & $\mathbf{0}$ & 80 & 71 & 71 & $\mathbf{0}$ & 80 & 79 & 61 & 71 & $\mathbf{0}$ & 61 & 61 & 61 & 79 & - & 84 & $\mathbf{0}$ \\
19 & 76 & 76 & 76 & 0 & 83 & $\mathbf{0}$ & $\mathbf{0}$ & $\mathbf{0}$ & 83 & 81 & 71 & 71 & $\mathbf{0}$ & $\mathbf{0}$ & $\mathbf{0}$ & 77 & 79 & 84 & - & $\mathbf{0}$ \\
20 & 52 & $\mathbf{0}$ & $\mathbf{0}$ & 52 & $\mathbf{0}$ & $\mathbf{0}$ & 52 & 52 & $\mathbf{0}$ & $\mathbf{0}$ & 71 & 79 & 52 & 52 & 52 & 77 & $\mathbf{0}$ & $\mathbf{0}$ & $\mathbf{0}$ & - \\
\hline & & & & & & & & & & & & & & & & & &
\end{tabular}

- The probability of failure of each link equals the percentage of damage to that link multiplied by the probability of building collapse;

- Impassable links containing collapsed bridges have a failure probability of $100 \%$.

\section{Results}

All O-D pairs were used to calculate the reliability of the network. Table 4 shows the resulting $20 \times 20$ matrix for network reliability. All computations in the simulation were carried out on a $\mathrm{PC}$ with a $2.8 \mathrm{GHz}$ processor and 2 GB RAM; the algorithm was executed in MATLAB 7.0. In the table, zero reliability resulted from collapsed bridges in the shortest path. The shortest path between O-D pairs, where at least one link contains a collapsed bridge and is unusable, records a failure probability of $100 \%$.

It can be seen that most paths to or from district 19 contain a collapsed bridge. This indicates that district 19 may have problems in the evacuation, and search and rescue stages of disaster response. It was found that connectivity reliability for origins and destinations between districts 1 to 5 was much higher than for other districts, especially districts $6,18,19$, and 20, which were high-population-density areas of Tehran. It appears that northern regions of Tehran will remain connected after an earthquake. The central and southern districts appear to have problems for access to search and rescue after an earthquake. This raises the need to improve disaster management or improve the roadway network in these districts. Table 5 is an exam-

Table 5. Reliability calculation for sample O-D pair.

\begin{tabular}{ccccc}
\hline O-D pair & $\begin{array}{c}\text { Randomly generated } \\
\text { numbers }\end{array}$ & $\begin{array}{c}\text { CPU time } \\
(\mathbf{s})\end{array}$ & $\begin{array}{c}\text { Connectivity } \\
\text { reliability }\end{array}$ & $\begin{array}{c}\text { Difference between } \\
\text { reliabilities }\end{array}$ \\
\hline 10 & 0.04 & 0.977 & - \\
& 100 & 0.07 & 0.929 & 0.048 \\
$(1,2)$ & 1000 & 2 & 0.881 & 0.048 \\
& 10000 & 7.02 & 0.822 & 0.059 \\
& 100000 & 63.8 & 0.8202 & 0.0018 \\
& 1000000 & 612.4 & 0.8199 & 0.0003 \\
\hline
\end{tabular}


ple of reliability calculation for one O-D pair presented in Table 4. In this table, the convergence of reliabilities after generating more than 100000 random numbers for the probability of survival of a link is evident.

\section{Conclusion}

This study introduced a new method for estimating the reliability of a roadway network after an earthquake by considering the physical characteristics of the road and adjacent buildings and link capacity degradation. The method was applied to a real roadway network and the results of connectivity reliability were presented. The new connectivity reliability technique is sensitive to the characteristics of the roads and adjacent buildings. The results indicate that districts 1 to 5 with a low population density, newer buildings, and highway network have higher reliabilities as the origin or destination of other districts in Tehran. The probability of connectedness of these districts to others after the hypothetical earthquake is high compared to other districts. The weakest areas of the network were in south and central districts 6, 7, 8, 18, 19, and 20 that had older buildings and high population density. These results provide useful insights into weaknesses of the Tehran transportation network which is highly vulnerable to a major earthquake.

The results also showed that the failure (collapse) of a bridge strongly affects the reliability of an O-D pair if that bridge is on the shortest path. Debris from a building on a roadway can be removed, but the loss of a bridge makes the road impassable. The square footage and type of facility should be considered when determining the failure of adjacent buildings. It is a topic of future research. Tall slender buildings are more likely than short wide buildings to fall onto roadways. The choice of alternate route choice options other than shortest path is another topic of future research. Future study could focus on identification of the most reliable rescue paths to the locations where buildings are most likely to fail so that rescue vehicles can reach those areas.

\section{Acknowledgements}

The authors would like to thank Dr. Poorzahedy of Sharif University of Technology for his constructive comments and recommendations and great helps in providing the travel demand and traffic data. However, they remain solely responsible for the content of this paper.

\section{References}

1. Derabek, T. and Watmer, J.H. "Disaster management, principles and guide for local governments", Research and Planning Center of Tehran, Tehran, 1, pp. 110-214 (2004).

2. Sumalee, A. and Kurauchi, F. "Network capacity reliability analysis considering traffic regulation after a major disaster", Journal of Network Spatial Economics, 6, pp. 205-219 (2006).

3. Nicholson, A. and Du, Z.P. "Degradable transportation systems: An integrated equilibrium model", Transportation Research Record: Journal of the Transportation Research Board, 31(B), pp. 209-224 (1997).

4. Sumalee, A. and Watling, D. "Travel time reliability in a network with dependent link modes and partial driver response", Journal of Eastern Asia Society for Transportation Studies, 5, pp. 1686-1701 (2003).

5. Bell, M.G.H. and Iida, Y., Transportation Network Analysis, John Wiley \& Sons, Inc., New York (1997).

6. Bell, M.G.H., Cassir, C., Iida, Y. and Lam, W.H.K. "A sensitivity based approach to reliability assessment", Proceedings of the 14 th International Symposium on Transportation and Traffic Theory, pp. 283-300 (1999).

7. Asakura, Y., Reliability Measures of an Origin and Destination Pair in a Deteriorated Road Network with Variable Flows, Transportation Networks: Recent Methodological Advances, Pergamon Press, Oxford, pp. 273-288 (1996).

8. Morlok, E.K. and Chang, D.J. "Measuring capacity flexibility of a transportation system", Transportation Research. Part A, Policy and Practice, 38(6), pp. 405420 (2004).

9. Chen, A., Yang, H., Lo, H.K. and Tang, W.H. "A capacity related reliability for transportation networks", Journal of Advanced Transportation, 33, pp. 183-200 (1999).

10. Chen, A., Yang, H., Lo, H.K. and Tang, W.H. "Capacity reliability of a road network: an assessment methodology and numerical results", Transportation Research, Part B: Method logical, 36(3), pp. 225-552 (2002).

11. Chen, A. and Kasikitwiwat, A. "Assessing network capacity flexibility of a transportation network", Transportation Research Record: Journal of the Transportation Research Board, 24, pp. 145-157 (2003).

12. Nojima, N. and Chang, S.E. "Measuring post-disaster transportation system performance: the 1995 Kobe earthquake in comparative perspective", Transportation Research Record: Journal of the Transportation Research Board, 35(6), pp. 475-494 (2001).

13. Kawakami, H. "Earthquake performance of highway systems in Tokyo", Proceedings of the 12th World Conference on Earthquake Engineering, pp. 1-8 (2000).

14. Jiang, C., Wang, M., Wang, W. and Qiyun, P. "Reliability evaluation study on road networks in highintensity earthquake zones", Proceedings of the 14th International Conference on Transportation Engineering, pp. 564-568 (2002). 
15. Khademi, N., Balaei, B., Shahri, M., Sarrafi, B. and Mohaymany, A.S. "Transportation network vulnerability analysis for the case of a catastrophic earthquake", International Journal of Disaster Risk Reduction, 12, pp. 234-254 (2015).

16. Liu, R., Lin J., Fang, X. and Zhou, X. "Study on the post-earthquake connectivity of transportation system network", The 14th World Conference on Earthquake Engineering (2008).

17. Li, B., Hu, X. and Xie, B., Transportation Network Reconstruction for Natural Disaster in the Emergency Phase Based on Connectivity Reliability, ICTE (2009).

18. Mohaymany, S.A., Kalantari, N., Mesbah, M. and Mohammadia, P. "Identifying critical infrastructures in road network based on emergency response accessibility", Proceedings of the 14 th International Conference on Earthquake Engineering, Paper No. 220 (2006).

19. Yang, H., HK, L. and Tang, W.H., Combining Travel Time and Capacity Reliability for Performance Measure of a Road Network, The Hong Kong University of Science and Technology, P.R. China Research Studies Press Ltd. (2000).

20. Gertsbakh, I. and Shpungin, Y. "Optimal reliability design of transportation network", Proceedings of the 10th International Conference on Reliability and Statistics in Transportation and Communication, pp. 10-24 (2010).

21. Emam, B.E. and al-Deek, H., Utilizing a Real Life Dual Loop Detector Data to Develop a New Methodology for Estimating Freeway Travel Time Reliability, Presented at 85th Annual Meeting of the Transportation Research Board, Washington, D.C. (2006).

22. Gunnec, D. and Salman, S.F. "Assessing the reliability and the expected performance of a network", $O R$ Spectrum, 33(3), pp. 499-523 (2011). Available at: www.euro-online.org/enog/inoc2007/Papers/authors /paper.108.pdf. Accessed 5 Mar 2007.

23. Sumalee, A. and Watling, D.P. "Partition-based algorithm for estimating transportation network reliability with dependent link failures", Journal of Advanced Transportation, 85(1), pp. 138-147 (2008).

24. Transportation and Traffic Group "Latest Tehran transportation model in EMME2 software", Tehran Traffic and Transportation Studies Center, Report No.117 (1996).

25. Watling, D., Sumalee, A., Connors, R. and Balijepalli, C. "Advancing methods for evaluating network reliability", A Department for Transport New Horizons Project, Final Report, Institute for Transport Studies, University of Leeds (2004).

26. Japan International Cooperation Agency (JICA) and Centre for Earthquake and Environmental Studies of Tehran (CEST)., The Study of Seismic Micro Zoning of the Greater Tehran Area in the Islamic Republic of Iran, Tehran Municipality, Final Report (2000).

\section{Biographies}

Kaveh Shabani is a senior analyst at RSG Inc., San Diego, California. He received a Master of Transportation Planning degree from Portland State University, Portland, Oregon, and Bachelor's and Master's degrees in Civil Engineering and Transportation Planning from Sharif University of Technology, Tehran, Iran. Joining RSG in 2012, Dr. Shabani has been responsible for the development of advanced freight models and analysis of freight data sources.

Habibollah Nassiri is an Associate Professor of Civil Engineering at Sharif University of Technology. He received his $\mathrm{PhD}$ degree from Texas A \& M University, USA, in 1989 specializing in Transportation Planning, and MS and BS degrees in Civil Engineering from Auburn University, USA His research interests are transportation planning, and traffic engineering, highway design and traffic safety, and traffic monitoring. 